\title{
A RESISTÊNCIA À EMPIRIA
}

\author{
Rachel Esteves Lima* \\ Universidade Federal da Bahia / CNPq
}

\begin{abstract}
RESUMO
O trabalho tem como objetivo questionar a forma como, há décadas, se vem naturalizando a mega-hipótese de que estaria ocorrendo, no meio literário, uma "crise da literatura comparada" e/ou uma "crise da crítica", sem que tal ideia seja legitimada por pesquisas sobre as estratégias interpretativas que vêm sendo efetivamente colocadas em prática nesses campos de produção de conhecimento. Nesse sentido, pretende-se apontar para a necessidade de se promoverem investigações que historicizem as transformações por que vêm passando os estudos literários a partir de metodologias mais consistentes de levantamento e descrição de dados, visando à formação de arquivos que possam fornecer subsídios não apenas para se verificar em que medida as visões apocalípticas que insistem em denunciar a falência da faculdade do juízo e o predomínio do relativismo cultural possuem ou não pertinência, mas também para a observação e a análise dos diversos modos de leitura que concorrem pela hegemonia na universidade e nos congressos da área.
\end{abstract}

\section{PALAVRAS - CHAVE}

Crise da literatura comparada, metacrítica, leitura empírica do comparatismo

O objeto não é senão o correlato da prática. Uma noção que não se traduz em nada de efetivo não passa de uma palavra.

Paul Veyne

Aparentemente, a utilização paródica do título do célebre artigo em que Paul de Man ${ }^{1}$ discute o processo de "resistência à teoria" que estaria em curso nos Estados Unidos nos anos 1970/80, com a crescente incorporação das propostas de teóricos da leitura de perspectivas diversas, como Greimas, Riffaterre, Jauss e Iser, responsáveis por deslocar os estudos retóricos praticados pelos adeptos do close reading e dos procedimentos analíticos defendidos pelos teóricos da Desconstrução, pode levar a crer que se trata,

\footnotetext{
* rachellima@uol.com.br

${ }^{1}$ DE MAN. A resistência à teoria, p. 23-41.
} 
neste trabalho, de uma nítida oposição ao pensamento do autor. É necessário, no entanto, esclarecer, logo de início, que talvez possamos, no máximo, considerar esse gesto de apropriação como uma paródia pós-moderna, no sentido atribuído por Linda Hutcheon, ${ }^{2}$ de que, na contemporaneidade, esse tropo pode ser visto como uma inserção numa certa tradição interpretativa, mas, ao mesmo tempo, como um ato interessado em promover a autorreflexividade indispensável para operar os deslocamentos dos sentidos ao longo da história. Assim, a noção de empiria, aqui utilizada, não visa a um retorno a certo positivismo historicista, a uma adesão incondicional aos princípios teóricos da Ciência da Literatura Empírica ou mesmo a um alinhamento irrestrito aos procedimentos analíticos da Estética da Recepção, condenados como excessivamente técnicos por De Man. Tampouco pretende desconsiderar a importância de leituras que optem pela crítica textual, priorizando a análise dos aspectos formais. O que se busca com o título deste trabalho é discutir os rumos da Literatura Comparada na contemporaneidade, chamandose a atenção para a necessidade de se investir em um trabalho historiográfico sobre as transformações ocorridas nesse campo disciplinar que, de fato, articule a teoria à prática, o que, infelizmente, ainda não tem ocorrido como seria desejável. Ao insistir na necessidade de uma "operação histórica" que lance novas luzes sobre a Literatura Comparada, faço eco à visão de Michel de Certeau, segundo a qual a história é sempre ambivalente, "uma vez que o lugar que ela corta ao passado é igualmente uma maneira de dar lugar a um futuro". ${ }^{3}$ Neste ensaio, recortamos, pois, um passado de discussões sobre a crise da Literatura Comparada, ocorridas no âmbito dos congressos da Associação Brasileira de Literatura Comparada, visando evidenciar a diferença desse passado em relação ao presente e, dessa forma, simbolizar os nossos atuais limites, na tentativa de contribuir para "a partir daí tornar possível uma ultrapassagem". ${ }^{4}$ Para isso, tomamos como ponto de partida o arquivo constituído pelos 13 números publicados da Revista Brasileira de Literatura Comparada (RBLC), ${ }^{5}$ editada pela Associação e disponibilizada na página da ABRALIC. ${ }^{6}$

Uma breve visita a esse arquivo é suficiente para verificarmos uma mudança na linha editorial da revista. Se, conforme afirma Iris $\mathrm{Hoisel}^{7}$ em um dos raros ensaios publicados nos Anais dos Congressos da ABRALIC que tomam como corpus de análise os discursos publicados sob a chancela dessa Associação, até o n. 4 se podia encontrar uma significativa quantidade de textos que tinham como objetivo produzir uma reflexão sobre as teorias e práticas da Literatura Comparada, a partir de então tais textos vão se tornando mais e mais escassos, a ponto de praticamente desaparecerem nos dois últimos números. Tal fato, por si só, não nos autoriza a dizer que houve uma acomodação em relação aos frequentes questionamentos acerca da amplitude fenomenológica dos

\footnotetext{
${ }^{2}$ HUTCHEON. Póetica do pós-modernismo. ${ }^{3}$ CERTEAU. A operação histórica, p. 41. (grifos do autor)

${ }^{4}$ CERTEAU. A operação histórica, p. 41.

${ }^{5}$ Doravante, a revista será apresentada sob a sigla RBLC.

${ }^{6} \mathrm{Cf} .<$ http://www.abralic.org.br/revista $>$.

${ }^{7}$ HOISEL. O debate disciplinar na Revista Brasileira de Literatura Comparada.
} 
trabalhos desenvolvidos nesse campo, que, principalmente até 1998, movimentaram as discussões no meio acadêmico brasileiro. Mesmo porque, por diversas vezes, as gestões da Associação optaram por publicar os textos que tratam desse tema em livros especificamente destinados a esse fim. ${ }^{8}$ No entanto, não se pode também desconsiderar que essa mudança de orientação da revista vai de par com uma fragmentação do espaço para discussões no âmbito da Associação, assim como com a decisão de limitar o número de inscrições no último Congresso Internacional, realizado em 2008. Além disso, não se pode deixar de levar em conta que a atual gestão deixa clara em sua página na internet a existência de duas propostas para a Associação: transformar-se em ABRALIT Associação Brasileira de Literatura ou "voltar a seus propósitos iniciais, concentrandose em organizar eventos de literatura comparada em sentido restrito e, consequentemente, diminuindo drasticamente seu tamanho". ${ }^{9}$ Diante desse quadro, faz-se necessária a promoção de um debate que possa recuperar as contribuições do passado para tentar evitar que se chegue a um retrocesso no futuro.

Em um dos textos da fase autorreflexiva da RBLC, ainda no período de consolidação da ABRALIC, a dificuldade encontrada na terminologia utilizada para designar e delimitar as várias disciplinas que têm a literatura como objeto foi justificada por Tania Carvalhal pelo fato de elas se imbricarem, "redefin[ir] em constantemente seus próprios estatutos e modifica[re]m freqüentemente seus dispositivos teóricos". ${ }^{10}$ A ideia de que a Literatura Comparada seria uma disciplina constantemente em crise tem sua origem, por sua vez, na célebre conferência de René Wellek, de 1958, na qual o teórico buscou renovar os estudos comparatistas, distanciando-os do historicismo positivista e aproximando-os dos princípios de correntes imanentistas como o new criticism e o formalismo russo. ${ }^{11}$ A recorrência a esse texto seminal tem sido uma constante nas reflexões desenvolvidas nesse campo, sempre que se fazem perceptíveis algumas mudanças paradigmáticas nos estudos comparatistas. Talvez se possa mesmo dizer que houve uma naturalização da ideia de crise nos discursos produzidos sobre a Literatura Comparada, podendo-se perceber duas vias para se compreender o seu caráter mutante: de um lado, postam-se os que defendem o nomadismo da disciplina como prova de seu vigor e, de outro, os inconformados com a expansão de seu raio de ação e com a incorporação de teorias que desestabilizam os modelos interpretativos antes hegemônicos. De modo geral, os opositores da mudança referem-se à identificação dos estudos comparatistas com os pressupostos teóricos dos Estudos Culturais de matriz norte-americana, que vêm questionando, no terreno da literatura, a subordinação da análise dos textos à crítica ideológica, a perda da especificidade do literário frente à ampliação do campo de atuação dos estudos da área, a disseminação de um ecletismo sem rigor metodológico, a importação

\footnotetext{
${ }^{8}$ Como exemplos, podem ser citadas as seguintes publicações: ANTELO et al. Declínio da arte, ascensão da cultura; ANDRADE; CAMARGO; ANTELO. Leituras do ciclo; e MARQUES; VILELA. Valores: Arte, Mercado, Política.

${ }^{9}$ Disponível em: < http://www.abralic.org/htm/congressos/planejamento2009-11.htm >. Acesso em: 10 ago. 2009.

${ }^{10}$ CARVALHAL. Teorias em Literatura Comparada, p. 10.

${ }^{11}$ Cf. WELLEK. A crise da Literatura Comparada.
} 
acrítica de modismos teóricos e o relativismo cultural, que pressupõe a revisão do cânone literário, normalmente formado por "autores homens, brancos e mortos". Da mesma forma, os defensores da abordagem marxista reclamam a ausência de um projeto político, geralmente compreendido a partir da noção de luta de classes, conceito que será doravante substituído pela agenda de interesses multiculturais relativos aos gender e ethnic studies. No caso da América Latina, há ainda o questionamento do caráter neocolonialista da importação das categorias de análise dos Estudos Culturais estadunidenses pela intelectualidade periférica, deixando-se em segundo plano uma série de construtos teóricos que, no próprio subcontinente, já vinham sendo desenvolvidos para lidar com os processos interculturais situados em sociedades multiétnicas, que se modernizam de modo descompassado e desigual. ${ }^{12}$

Alinhada à primeira vertente, que se recusa a corroborar o tom apocalíptico implícito na crítica à denominada crise da Literatura Comparada, Eneida Maria de Souza, no texto "A teoria em crise", publicado no número 4 da RBLC, alerta quanto ao risco inerente à permanência dos pesquisadores em posições teóricas já consolidadas:

Infelizmente, torna-se tarefa impossível conservar, na atualidade, posições radicais contra os desmandos da teoria e o descontrole dos paradigmas de referência. O mundo mudou, nos últimos dez anos, de forma assustadora (para o bem ou para o mal), e por que motivo as concepções artísticas, teóricas e políticas não deveriam também trocar o caminho tranqüilizador do reconhecimento pelo do saber sempre em processo? Enfrentar esse desafio é uma das formas de continuar a mover o debate teórico, para que este não se transforme em consenso de grupos ou na apatia acadêmica, provocada por um certo tipo de mal-estar, que não incita a curiosidade, mas, ao contrário, alimenta o conservadorismo. ${ }^{13}$

A julgar pelas alternativas apontadas pela atual gestão da ABRALIC, assim como pela ausência desse debate nas páginas dos números mais recentes da RBLC, talvez devamos reconhecer que essa apatia acabou por prevalecer, em detrimento da vitalidade das discussões, e os resultados sinalizados por Souza se mostram hoje mais visíveis do que nunca.

Também no mesmo número da revista no qual se publicou o ensaio "A teoria em crise", Wander Melo Miranda, no texto "Projeções de um debate", procura responder aos críticos que, a exemplo de Leyla Perrone-Moisés e Luiz Costa Lima, questionam o desmoronamento dos limites disciplinares responsáveis pelo suposto "vale tudo" que estaria predominando nos congressos da ABRALIC, ressaltando a natureza metateórica da Literatura Comparada, ao alegar que "a perplexidade diante da nova situação, que para muitos se traduz pela perda de identidade do objeto, é indício menos de uma crise do que a reafirmação, em termos radicais, de que o objeto da comparatística é o seu campo". ${ }^{14}$ Considerando pertinente tal afirmação, perguntamo-nos, porém, acerca da razão pela qual esse campo só é analisado, nos diversos textos que ativaram o debate a partir do V Congresso da ABRALIC, realizado em 1996, a partir das diferentes teorias

\footnotetext{
${ }^{12}$ Cf. YÚDICE. Estudios y otras prácticas intelectuales latinoamericanas en cultura y poder.

${ }^{13}$ SOUZA. A teoria em crise, p. 29.

${ }^{14}$ MIRANDA. Projeções de um debate, p. 11. (grifos do autor)
} 
em conflito, sem se tomar como ponto de partida uma análise do arquivo composto pela totalidade ou, pelo menos, pela grande maioria dos trabalhos apresentados nos diversos eventos da Associação. Ao defender a visão de que caberia aos estudos comparados a tarefa de questionar o processo de formação de valores a partir de um viés universalista e totalizante, tal como propõe George Yúdice para os Estudos Culturais, o autor de Corpos escritos recusa-se a vincular o comparatismo à "compulsão documental" e à "avaliação unívoca que por vezes circunscrevem os estudos culturais à esfera de um novo empirismo". ${ }^{15}$ Acreditamos que o crítico procura, aqui, fazer menção às limitações inerentes às políticas de identidade, em um sentido restrito. No entanto, não se pode descartar a ideia de que parece prevalecer nessa afirmação uma visão que, infelizmente, acaba por manter a dicotomia existente entre a teoria e a prática, cuja dissolução, inspirada pelas propostas de Deleuze e Foucault, ${ }^{16}$ podem ser consideradas como um dos principais méritos dos Cultural Studies. Afinal, o questionamento do caráter autônomo e desinteressado da produção científica e artística, promovido por essa corrente teórica, é responsável por uma maior implicação dos sujeitos no processo de produção do conhecimento, fazendose necessário, portanto, um esforço de historicização que seja capaz de correlacionar as diversas práticas discursivas aos seus respectivos lugares de enunciação, se se quiser, efetivamente, compreender os modos de formação dos valores da bolsa literária.

O que se defende aqui, portanto, é uma articulação entre teoria e prática que, na esteira do trabalho historiográfico desenvolvido por Michel Foucault, Paul Veyne e Michel de Certeau, seja capaz de desconstruir tanto as acepções cristalizadas para os conceitos que utilizamos para lidar com nossos objetos de estudo quanto o dogmatismo dos valores eternos. Para tanto, necessário se faz correlacionar as práticas discursivas do campo da Literatura Comparada aos seus loci de produção. A adoção de uma perspectiva genealógica, tal como definida por Foucault a partir das proposições nietzschianas, ${ }^{17}$ visaria menos à produção de uma história concebida a partir da ação dos epígonos da área da Literatura Comparada, do que às ações descontínuas dos praticantes dessa disciplina, que hoje, dada a expansão dos cursos de pós-graduação da área de Literatura, podem estar constituindo o que se vem denominando como uma "intelectualidade de massa", ${ }^{18}$ capaz de minar os consensos, instaurando em seu lugar a heterogeneidade das opções teóricas que vêm sendo seguidas e a pluralidade dos modos de leitura e avaliação dos bens simbólicos. Um trabalho dessa natureza deixaria de assumir um tom prescritivo, restringindo-se a uma descrição que busque ser, na medida do possível, isenta de pressuposições, de modo a evitar a recaída em modelos explicativos de ordem causal que determine a ordem dos condicionantes. Pois, segundo Paul Veyne, "o que é feito, o objeto, se explica pelo que foi o fazer em cada momento da história; enganamo-nos quando pensamos que o fazer, a prática, se explica a partir do que é feito". ${ }^{19}$ Assim se

\footnotetext{
${ }^{15}$ MIRANDA. Projeções de um debate, p. 12.

${ }^{16}$ FOUCAULT, DELEUZE. Os intelectuais e o poder.

${ }^{17}$ FOUCAULT. Nietzsche, a genealogia e a história.

${ }^{18}$ Cf. GORZ. O imaterial: conhecimento, valor e capital; HARDT, NEGRI. Império; HARDT; NEGRI.

Multidão; e LAZZARATO. As revoluções do capitalismo.

${ }^{19}$ VEYNE. Foucault revoluciona a história, p. 164. (grifos do autor)
} 
procedendo, a frase proferida por Wander Melo Miranda - "o objeto da comparatística é o seu campo" - adquire um sentido suplementar, cabendo a nós, pesquisadores, o imperativo de ir aos arquivos - nosso espaço privilegiado de investigação - em busca de respostas para os impasses que ora se apresentam.

$\mathrm{Na}$ atualidade, tal tarefa mostra-se bastante facilitada pela disponibilização desses arquivos na internet. Assim, além das revistas de que nos utilizamos para a produção deste ensaio, os anais dos congressos da ABRALIC vêm sendo gradativamente alocados na página da Associação. Além disso, os cursos de pós-graduação mantêm, hoje, bancos virtuais de teses e dissertações que podem ser consultados, o que facilita a verificação dos modos de configuração das diversas comunidades interpretativas em atividade nos cursos de Letras do país. A análise particularizada dos resultados colhidos nas várias instituições de ensino superior pode nos fornecer uma visão mais precisa acerca das teorias e procedimentos metodológicos utilizados nas leituras comparatistas, assim como dos objetos de estudo que vêm sendo realizados ao longo do tempo. A partir dessas descrições, faz-se possível produzir, então, uma leitura "polemológica"20 dos diversos espaços de produção de saberes em âmbito nacional, levando-se sempre em consideração a posição de Pierre Bourdieu, segundo a qual "as escolas de pensamento contêm também pensamentos de escola”. ${ }^{21}$ Em sua análise acerca das funções cumpridas pela escola na formação dos hábitos culturais, o sociólogo francês afirma que ela

não fornece apenas indicações, mas também define itinerários, ou seja, no sentido primeiro, métodos e programas de pensamento. Os esquemas intelectuais e lingüísticos organizam um espaço balizado, eivado de sentidos obrigatórios e de sentidos proibidos, de avenidas e impasses: no interior desse espaço, o pensamento pode manifestar-se com o sentimento da liberdade e da improvisação porque os itinerários já de antemão esboçados que deverá seguir, são os mesmos antes diversas vezes percorridos no curso das aprendizagens escolares. $^{22}$

Evidentemente, aqui devemos recusar o tom determinístico presente no fragmento citado, lembrando que a noção de habitus do autor visa justamente à afirmação do caráter performático da construção das identidades no interior da sociedade, relativizando-se, dessa forma, a associação direta dos modos de apropriação dos bens simbólicos com as formas de distinção normalmente atribuídas às classes sociais. A perspectiva genealógica aqui defendida referenda, pois, a percepção de que as ideias se reproduzem no interior das instituições, mas ao mesmo tempo compreende o fato de que essas ideias também se transformam a partir da intervenção dos diversos agentes do campo intelectual nos espaços em que atuam. Propõe-se, dessa forma, não apenas o estudo das regularidades, mas, também, e principalmente, a observação das "táticas desviacionistas", que traçam, conforme afirma de Certeau, as "trilhas heterogêneas onde se infiltram e onde se esboçam as astúcias de interesses e de desejos diferentes". ${ }^{23}$

\footnotetext{
${ }^{20}$ Cf. CERTEAU. A invenção do cotidiano. 1: Artes de fazer, p. 44-45.

${ }^{21} \mathrm{Cf}$. BOURDIEU. A economia das trocas simbólicas, p. 210.

${ }^{22}$ BOURDIEU. A economia das trocas simbólicas, p. 214.

${ }^{23}$ CERTEAU. A invenção do cotidiano. 1: Artes de fazer, p. 97. (grifos do autor)
} 
A partir de pesquisas historiográficas dessa natureza se poderia contribuir para dar visibilidade às novas forças e subjetividades que emergem hoje no terreno da crítica, evidenciando-se ainda se, de fato, a difusão dos Estudos Culturais no campo da Literatura Comparada teve como consequência o abandono da literatura como instância privilegiada nas leituras realizadas pelos analistas do campo, se a incorporação das teorias estrangeiras representou, como se alegou, o desprestígio dos conceitos operatórios construídos no âmbito local e regional, se os instrumentos analíticos de base formalista foram efetivamente relegados a segundo plano, se os estudos sobre as identidade limitamse a reverter a visão moderna, recaindo-se no essencialismo que se pretendeu descartar, se realmente a faculdade do juízo se encontra em baixa na contemporaneidade, se a exposição do caráter subjetivo das interpretações elide a argumentação necessária para sustentar o rigor dos trabalhos científicos, dentre outras possibilidades. Não obstante, considerando-se o inexpressivo número de publicações decorrentes de pesquisas que procedam a essa deontologia, conclui-se que a área ainda apresenta resistências a assumir a autorreflexividade como um dos parâmetros para a definição de suas políticas, optando por valorizar apenas o cinza da teoria, a que se referiu Goethe, ${ }^{24}$ esquecendo-se de combiná-lo ao cinza da história genealógica, defendida por Michel Foucault. ${ }^{25} \mathrm{~A}$ permanecermos nessa situação, o prognóstico do conservadorismo enunciado por Eneida Maria de Souza tende mesmo a se transformar em realidade.

\section{(4)}

\section{A B STRACT}

The aim of this piece is to call into question the manner in which, for decades, we have been witnessing the naturalization of a mega-hypothesis according to which there has been taking place, in the literary milieu, a "crisis of comparative literature" and/or a "crisis of criticism", even if such a notion has not been borne out by research into the interpretive strategies effectively being put into practice in these fields of knowledge production. In this sense, we seek to point out the need for investigations that should historicize the transformations undergone by the literary studies since the implementation of more consistent methodologies for data gathering and description, which aim to put together archives that may provide support not only for those willing to ascertain to what extent the apocalyptical visions that insist on denouncing the failure of the faculty of judgement do or do not obtain, but also for the observation and analysis of the several reading modes which vie for hegemony at the university and the congresses of the area.

\section{KEYWORDS}

Crisis of comparative literature, metacriticism, empirical reading of comparatism

\footnotetext{
${ }^{24}$ Diria o poeta em GOETHE. Fausto zero (Urfaust), p. 51: "Cinza, caro amigo, é toda teoria".

${ }^{25}$ FOUCAULT. Nietzsche, a genealogia, a história, p. 15.
} 


\section{REFERÊNCIAS}

ANDRADE, Ana Luíza; CAMARGO, Maria Lúcia Barros; ANTElO, Raúl (Org.). Leituras do ciclo. Ilha de Santa Catarina/Chapecó: ABRALIC, 1999.

ANTELO, Raúl et al. Declínio da arte, ascensão da cultura. Florianópolis: ABRALIC; Letras Contemporâneas, 1998.

BOURDIEU, Pierre. A economia das trocas simbólicas. Trad. Sergio Miceli et al. São Paulo: Perspectiva, 1992.

CARVAlHAL, Tania Franco. Teorias em Literatura Comparada. Revista Brasileira de Literatura Comparada, n. 2, p. 9-17, maio 1994.

CERTEAU, Michel de. A operação histórica. In: In: LE GOFF, Jacques; NORA, Pierre (Org.). História: novos problemas. 3. ed. Trad. Theo Santiago. Rio de Janeiro: Francisco Alves, 1988. p. 17-48.

CERTEAU, Michel de. A invenção do cotidiano. 1: Artes de fazer. Trad. Ephraim Ferreira Alves. Petrópolis: Vozes, 1994.

DE MAN, Paul. A resistência à teoria. Trad. Teresa Louro Pérez. Lisboa: Edições 70, s.d. FOUCAULT, Michel; DELEUZE, Gilles. Os intelectuais e o poder. In: FOUCAULT, Michel. Microfísica do poder. 7. ed. Organização e trad. Roberto Machado. Rio de Janeiro: Graal, 1979. p. 69-78.

FOUCAULT, Michel. Nietzsche, a genealogia e a história. In: - Microfísica do poder.

7. ed. Organização e trad. Roberto Machado. Rio de janeiro: Graal, 2006. p. 15-37.

GOETHE, Johann Wolfgang. Fausto zero (Urfaust). Trad. de Christine Röhrig. São Paulo: Cosac \& Naify, 2001.

GORZ, André. O imaterial: conhecimento, valor e capital. Trad. Celso Azzan Jr. São Paulo: Annablume, 2005.

HARDT, Michael; NEGRI, Antonio. Império. Trad. Berilo Vargas. Rio de Janeiro: Record, 2001.

HARDT, Michael; NEGRI, Antonio. Multidão. Trad. Clóvis Marques. Rio de Janeiro: Record, 2005.

HOISEL, Íris. O debate disciplinar na Revista Brasileira de Literatura Comparada. In: VIII Congresso ABRALIC, 2002, Belo Horizonte. Anais... Belo Horizonte: UFMG, 2002. Disponível em: < http://www.abralic.org.br/htm/congressos/anais-eventos.htm (S5C776) >. Acesso em: 08 ago. 2009.

HUTCHEON, Linda. Póetica do pós-modernismo. Trad. Ricardo Cruz. Rio de Janeiro: Imago, 1991.

LAZZARATO, Maurizio. As revoluções do capitalismo. Trad. Leonora Corsini. Rio de Janeiro: Civilização Brasileira, 2006.

MARQUES, Reinaldo; VILELA, Lúcia Helena (Org.). Valores: Arte, Mercado, Política. Belo Horizonte: Editora UFMG/ABRALIC, 2002.

MIRANDA, Wander Melo. Projeções de um debate. Revista Brasileira de Literatura Comparada, n. 4, p. 11-17, 1998. 
SOUZA, Eneida Maria de. A teoria em crise. Revista Brasileira de Literatura Comparada, n. 4, p. 19-29, 1998.

VEYNE, Paul. Foucault revoluciona a história. In: . Como se escreve a história. 3. ed. Trad. Alda Baltar e Maria Auxiliadora Kneipp. Brasília: UnB, 1995.

WELLEK, René. A crise da Literatura Comparada. In: COUTINHO, Eduardo; CARVALHAL, Tania Franco. Literatura Comparada: textos fundadores. Rio de Janeiro: Rocco, 1994. p. 108-119.

YÚDICE, George. Contrapunteo estadounidense/latinoamericano de los estudios culturales. In: MATO, Daniel (Comp.). Estudios y otras prácticas intelectuales latinoamericanas en cultura y poder. Caracas, Venezuela: CLACSO, Consejo Latinoamericano de Ciencias Sociales, 2002. Disponível em: < http://bibliotecavirtual.clacso.org.ar/ar/ libros/cultura/yudice.doc >. Acesso em: 08 ago. 2009. 